\title{
Subgrade Black Cotton Soil Stabilization using Ground Granulated Blast-Furnace Slag (GGBS) and Lime, an inorganic mineral
}

\author{
Bhanu Prakash Darsi ${ }^{1}$, Kumar Molugaram ${ }^{1,}$, and Saisantosh Vamshi Harsha Madiraju ${ }^{2}$ \\ 1 Department of Civil Engineering, University College of Engineering, Osmania University, Hyderabad, \\ TS, India, 500007; kumartrans@gmail.com \\ 2 Department of Civil and Environmental Engineering, College of Engineering, The University of Toledo, \\ Toledo, OH, USA 43606; smadira@rockets.utoledo.edu \\ * Correspondence: kumartrans@gmail.com;
}

Received: date; Accepted: date; Published: date

\begin{abstract}
The rapid growth of population and fast urbanization has resulted in the reduction of the good quality of available land. Black cotton (BC) soil is one of such problematic soils, though they are very fertile soils, they are not suitable for the foundation of roads and buildings. They are expansive clays with a high potential for shrinking or swelling as a result of changing moisture content. Due to the intensive shrink-swell process, surface cracks appear during dry seasons. A small amount of rainfall, such as $6 \mathrm{~mm}$ can make these soils impassable for all traffic. About $23 \%$ of the area in India is covered by BC soil. To utilize expansive soils effectively, proper ground improvement techniques are to be adopted. One of the most widely used techniques is to stabilize the expansive soil with conventional admixtures like lime, GGBS, cement, and fly ash. In the present study, an attempt is made to modify the engineering properties of black cotton soil. This research work presents the improvement of engineering characteristics of expansive soils using Lime and GGBS as an additive. For experimental work, Lime of $2 \%, 4 \%$, and $6 \%$ used and corresponding $5 \%$, and $10 \%$ of GGBS is used. Tests like the California Bearing Ratio (CBR) test, Unconfined Compression Strength (UCS) test, proctor test, Atterberg's limits performed. After stabilization, it was found that UCS and CBR of soil increased significantly.
\end{abstract}

Keywords: Soil stabilization, Black cotton soil, Lime, GGBS, California Bearing Ratio, Unconfined Compression Strength test, Proctor test.

\section{Introduction}

Subgrade soil is an important part of the road pavement structure as it provides support to the pavement layers like a subbase, base, and wearing courses from beneath. The properties of subgrade soil are very important for the design of a pavement structure. Any weakness in subgrade soil affects all the overlying layers of pavement especially flexible pavement. The subgrade should possess enough stability under adverse climatic conditions to provide support to the pavement. The formation of waves, corrugations, rutting, and shoving in blacktop pavements are due to poor subgrade conditions. Soil subgrades of granular nature will be having increased strength as compared to fine-grained soil [1]. Thus, pavements constructed on clayey soil require more pavement thickness. In some places natural soil available may be of this category and transportation of quality soil for replacement and pavement construction may involve huge costs. Thus, if the quality of weak soil can be improved using any low-cost waste materials, it will be an economical approach. Some of 
the problematic soil for pavement construction are collapsible soil, liquefiable soil, filling materials, loose deposits, swelling soil, and soft and marshy land [2]. One of the important modification techniques of fine-grained soils is mechanical stabilization or in other words, change in gradation. So, particles of various size ranges come in soil matrix so that voids formed will be minimum and a strong matrix with increased strength will be formed. Another method of soil improvement is chemical stabilization where conventional stabilizers like cement and lime are added to the soil, which due to some pozzolanic reactions create a strong cemented or bind-mix. But the use of cement for soil stabilization will result in elevated costs. Another method of subgrade improvement is grouting using cement, lime, bentonite, or other chemicals that fill voids in the soil resulting in increased strength and cohesion and reduced permeability, with no change in the volume of the original ground. But this method is too costly and can be applied in places where cost is not an important factor. It can also be used to cut off drainage properties in the soil to keep the pavement dry. One of the recent techniques used nowadays is the use of geosynthetics. Geosynthetics are planar products manufactured from polymeric materials used with soil or rock. These geosynthetics are of different types based on the method of manufacturing. They are geotextiles, geogrids, geomembranes, geo-composites, etc. The different geosynthetic membranes have been used to avoid different problems in the soil such as avoiding pumping out of soil material by providing a layer of geomembrane to waterproof the subgrade. It is also provided above the subgrade to provide more support due to its tensile nature which prevents undulations formed on the subgrade due to loads acting and prevents permanent damages on the road. Construction and demolition waste form another material that can be used for subgrade improvement. They are non-biodegradable. Thus, for reusing they can be segregated into different sizes. They when added to the soil can improve the CBR value. It can also be used as aggregates in concrete in rigid pavements. Some synthetic stabilizers like RBI grade 81, Terrazyme were also developed for subgrade improvement [4].

Due to industrialization, huge amounts of waste materials are generated which causes much pollution to the environment as well as takes a large area of useful land for dumping purposes. They are mostly non-biodegradable and remain in the environment for a long time. As the population increases waste generation also increases. Different types of industrial waste materials are fly ash, phospho-gypsum, blast furnace slags, lime kiln dust, cement kiln dust, red mud, jarofix, jarosite, steel slags, copper slags, plastic wastes, rubber wastes, rice husk ash, etc. [5]. These industrial wastes can also be blended with soil in different proportions to improve the properties required for subgrade material. Many of the above waste materials are pozzolanic which when mixed with soil in the presence of water form calcium silicate hydrates and calcium aluminum hydrates which can bind the soil matrix strongly [6]. Various studies are reported for the use of industrial waste materials for subgrade improvement [7]. The combined use of two wastes together for soil improvement can bring about improved properties as compared to individual use of any waste material. Such an approach is used in this research where waste materials like copper slag, fly ash, and cement kiln dust is used. Individual, as well as the combined use of these waste materials, are evaluated in this research for properties like Standard proctor test, Unconfined compressive strength test, and CBR test [8]. Limited studies are available in the literature for the usage of the above waste materials together for subgrade improvement. Rehana Rasool et al. (2017) had made efforts to improve various engineering properties of the soil by using waste material Ground Granulated Blast Furnace Slag (GGBS) as an alternative to lime or cement, to make it capable of taking more loads from the foundation structures. This paper includes the evaluation of soil properties like the unconfined compressive strength test and CBR test. In addition to that, different percentages of GGBS were added to find the variation in its original strength. Based on these results CBR test was performed with the GGBS percentages. From these results, it was found that optimum GGBS (18\%) gives the maximum increment in the CBR value compared with all the other combinations [9].

Nanda et al. (2016) have studied experimental investigations that are made to evaluate the unconfined strength including compaction characteristics of Lithomargic soil (shedi soil) stabilized with ground Granulated Blast furnace Slag (GGBS) and lime. It was found that the inclusion of lime can significantly enhance the UCS values of stabilized shed soil [10]. Abhijit et al. (2015) have 
conducted an experimental study to find the effect of ground granulated blast furnace slag (GGBS) and Sisal fibers on the mechanical properties of black cotton soil. In the initial, the basic properties of black cotton soil and sisal fiber were found out. The next phase focuses on the unconfined compressive strength and CBR values of the mixture of black cotton soil and the optimum dosage of GGBS randomly reinforced with varying percentages of sisal fibers. The results indicated that with the addition of GGBS to black cotton soil the maximum dry density increased, and optimum moisture content decreased. The unconfined compressive strength and CBR values increased the addition of sisal fibers to a mixture of black cotton soil and optimum dosage of GGBS. The highest result was obtained for a mixture of black cotton soil and optimum dosage of GGBS with $0.75 \%$ of sisal fibers [11]. Sravanthi et al. (2017) have done investigates to the effect of using Ground Granulated Blast Furnace Slag (GGBS) and Road Building International Grade-81 (RBI Grade- 81 ) at 2\%, 4\%, 6\% on the black cotton soil to improve the properties of soil. To know soil properties, tests such as Atterberg's limit, compaction test, CBR, UCS tests are carried out. From this investigation, the sub-grade soil can be improved by using RBI Grade-81 [12]. Geeta Rani et al. (2017) have carried out to estimate the optimal GGBS contents for the improvement of black cotton soil. To obtain the optimum content of GGBS, a UCS test was conducted. The UCC samples are tested under different curing periods (7 and 28 days) [13]. Dayalan (2016) has conducted experiments with different amounts of fly ash and GGBS. The performance of stabilized soil is evaluated using physical and strength performance tests like specific gravity, Atterberg limits, standard proctor test, and CBR test at optimum moisture content. From the results, it was found that the optimum value of fly ash is $15 \%$ and GGBS is $20 \%$ for stabilization of given soil based on CBR value determined [14]. Manjunath et al. (2012) have studied ground granulated blast furnace slag (an industrial waste) along with hydrated lime is used to stabilize a typical black cotton soil. Detailed experimental investigations have been carried out to know the effectiveness of the addition of slag and lime to improve the geotechnical properties of soil [15]. Harish (2017) has carried out a study stabilization of black cotton using lime. The test results have been shown that there is an improvement in strength properties of soil and a decrease in plasticity index substantial increase in CBR value has been observed in the increase in unconfined compressive strength values at different proportions of lime with age [16]. Saravanan et al. (2017) have carried out tests as per Indian Standards. He separated the test procedures into two phases, namely Stage-I and Stage-II. In Stage-I the soil tests include soil type, particle size distribution, soil index properties, standard proctor tests, shear tests, and CBR test. In Stage-II the soil tests include shear tests and CBR test for the suitable required proportions of GGBS along with lime in the collected soil samples. The test results from stage-I and stage-II are compared and from the study, it is inferred that the application of GGBS is a useful material for soil stabilization [17].

\section{Materials and Methods}

The soil was replaced by lime and GGBS at different proportions. Keeping 5\% GGBS as constant correspondingly $2 \%, 4 \%, 6 \%$ lime is used and keeping $10 \%$ GGBS as constant corresponding $2 \%, 4 \%$, $6 \%$ lime is used. Then accordingly different tests are performed on the mixed soil to know the index and engineering properties of soil. (Please see Figure 1 for the steps involved in methodology). The tests are considered from the Indian Standards (IS) [18-24].

\subsection{Grain Size Analysis}

Grain size analysis is carried out to determine the relative percentages of different sizes of particles in the sample. These sizes control the mechanical behavior of coarse-grained soil. The dry method of sieving is used for coarser fractions (retained on $4.75 \mathrm{~mm}$ sieve) and the wet method is used for finer fractions (retained on $75 \mathrm{micron}$ sieve) and the pipette method is used for fractions passing 75-micron sieve.

\subsection{Specific gravity}


The specific gravity test is conducted by the density bottle method. The specific gravity of solid particles is the ratio of the mass of a given volume of solids to the mass of an equal volume of water at $40 \mathrm{C}$.

\subsection{Atterberg Limits}

The Liquid and Plastic Limits (Atterberg Limits) of soil indicate the water contents at which certain changes in the physical behavior of soil can be observed. From Atterberg limits, it is possible to estimate the engineering properties of fine-grained soils. Plasticity is the property that enables a material to undergo deformation without noticeable elastic recovery and without cracking or crumbling. Plasticity is a major characteristic of soils containing an appreciable proportion of clay particles.

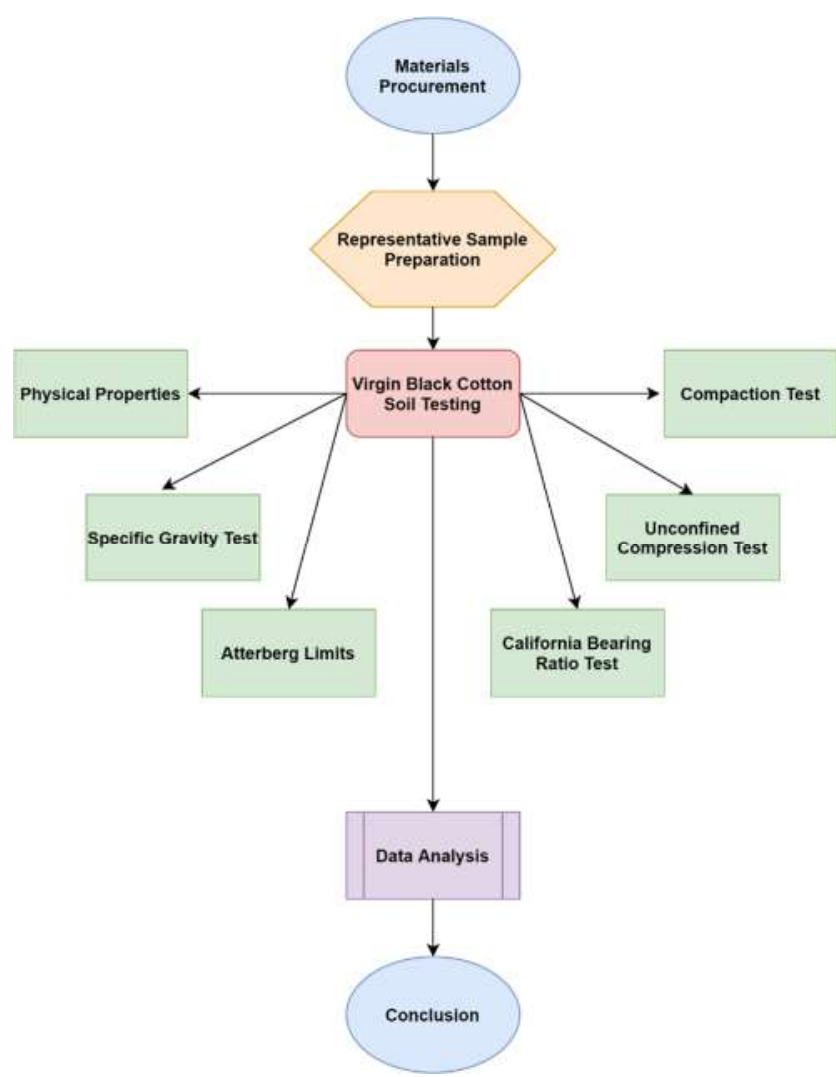

Figure 1. Flow chart representing the stepwise methodology implemented in the study

\subsection{Proctor Density}

Compaction is the process of densification of the soil mass by reducing air voids. The purpose of the laboratory compaction test so determines the proper amount of water at which the weight of the soil grains in a unit volume of the compacted is maximum, the amount of water is thus called the Optimum Moisture Content (OMC). In the laboratory, different values of moisture contents and the resulting dry densities, obtained after compaction are plotted both to arithmetic scale, the former as abscissa and the latter as ordinate. The points thus obtained are joined as a curve. The maximum dry density and the corresponding OMC are read from the curve.

Wet density = weight of wet soil in mold $g /$ volume of mold cc

Moisture content $\%=($ weight of water $(g) /$ weight of dry soil $(g)) * 100$

Drydensity $(g / c c)=$ wet density $(1+($ moisture content $/ 100))$

\subsection{CBR Test}

The CBR test is a penetration test meant for the evaluation of the subgrade strength of roads and pavements. $\mathrm{CBR}$ is the ratio of force per unit area required to penetrate a soil mass with a circular 
plunger of $50 \mathrm{~mm}$ diameter at the rate of $1.25 \mathrm{~mm} / \mathrm{min}$. The results obtained by these tests are used with the empirical curves to determine the thickness of pavement and its component layers. This is the most widely used method for the design of flexible pavement. Table 1. gives the standard loads used for different penetrations for the standard material with a CBR value of $100 \%$.

CBR $=($ Test load $/$ Standard load $) * 100$

Table 1. Standard loads used in CBR test.

\begin{tabular}{ll}
\hline Penetration of Plunger $(\mathbf{m m})$ & Standard Load $(\mathbf{k g})$ \\
\hline 2.5 & 1370 \\
5 & 2055 \\
7.5 & 2630 \\
10 & 3180 \\
12.5 & 3600 \\
\hline
\end{tabular}

\subsection{UCS Test}

The UCS test is by far the most popular method of soil shear testing because it is one of the fastest and cheapest methods of measuring shear strength. The method is used primarily for saturated, cohesive soils recovered from thin-walled sampling tubes. The UCS test is inappropriate for dry sands or crumbly clays because the materials would fall apart without some land of lateral confinement. To perform a UCS test, the sample is extruded from the sampling tube. A cylindrical sample of soil is trimmed such that the ends are reasonably smooth and the length to- diameter ratio is on the order of two. The soil sample is placed in a loading frame on a metal plate; by turning a crank, the operator raises the level of the bottom plate. The top of the soil sample is restrained by the top plate, which is attached to a calibrated proving ring. As the bottom plate is raised, an axial load is applied to the sample. The operator turns the crank at a specified rate so that there is a constant strain rate. The load is gradually increased to shear the sample, and readings are taken periodically of the force applied to the sample and the resulting deformation. The loading is continued until the soil develops an obvious shearing plane or the deformations become excessive. The measured data are used to determine the strength of the soil specimen and stress-strain characteristics.

\section{Results}

Determination of various physical and engineering properties namely Specific gravity, Liquid limit, Plastic limit, plasticity limit, Differential free swell index, Optimum moisture content, maximum dry density (MDD), Soaked CBR, UCS of the original soil, and various soil-industrial waste combinations. The soil samples required for the project i.e. black cotton soil, red soil, and moored were collected. A portion of these samples was taken to determine the index properties of the soil samples i.e. specific gravity, liquid limit, plastic limit, shrinkage limit, grain size distribution, optimum moisture content, and maximum dry density. The values obtained after testing were 18 Recorded. After knowing the optimum moisture content of the soil samples tests such as CBR, UCS Test, Bender Element Test was conducted on soil samples at optimum moisture content. To study the effect of stone dust on pavement subgrade soil various percentage of stone, dust is added to the soil samples ( $5 \%, 7 \% \& 10 \%)$. After adding the various percentages of stone dust to the soil samples CBR, UCS Test, Bender Element Test was conducted for each soil sample with a specific percentage of stone dust. The values obtained from the tests were recorded. The plastic limit and liquid limit of each sample were also tested and Recorded. These values were compared with the values obtained after testing soil samples at OMC to study the effect of stone dust on various index properties of pavement subgrade soil (see Table 2).

A standard proctor test was conducted on the original soil sample. MDD increased and after reaching an optimum it decreased. OMC obtained was $23.35 \%$ and MDD obtained was 1.647 . The compaction curve is as shown in Figure 2. An unconfined compressive strength test was conducted on a virgin soil sample. 3 samples were tested, and the average value obtained was taken as the UCS value. 
Table 2. Geotechnical properties of soil sample.

\begin{tabular}{ll}
\hline Property & Value obtained \\
\hline Specific gravity & 2.68 \\
Grain size distribution & \\
$\%$ of gravel & 8 \\
$\%$ of sand & 24.3 \\
$\%$ of silt & 28.7 \\
$\%$ of clay & 39 \\
Liquid limit & $58.2 \%$ \\
Plastic limit & $32.95 \%$ \\
Plasticity index & $25.25 \%$ \\
Free swelling index & $43 \%$ \\
Unconfined compressive strength & $174 \mathrm{KN} / \mathrm{m} 2$ \\
Standard proctor test MDD & $1.595 \mathrm{~g} / \mathrm{cc}$ \\
Optimum moisture content & $24 \%$ \\
CBR Un soaked & $8.02 \%$ \\
CBR Soaked & $4.1 \%$ \\
AASHTO Soil Classification System & $\mathrm{A}-7-6$ \\
Unified Soil Classification System & $\mathrm{CH}$ \\
\hline
\end{tabular}

The plot obtained for a specimen is as shown in Figure 3. CBR test was conducted on the virgin soil sample. After filling the soil in the mold in three layers, it was soaked in water for four days. Then testing was conducted on the CBR testing machine. The plot obtained is as shown in Figure 4 . The CBR value obtained was 2.11 making it a very poor subgrade material. For unsoaked CBR values see Figure 5.

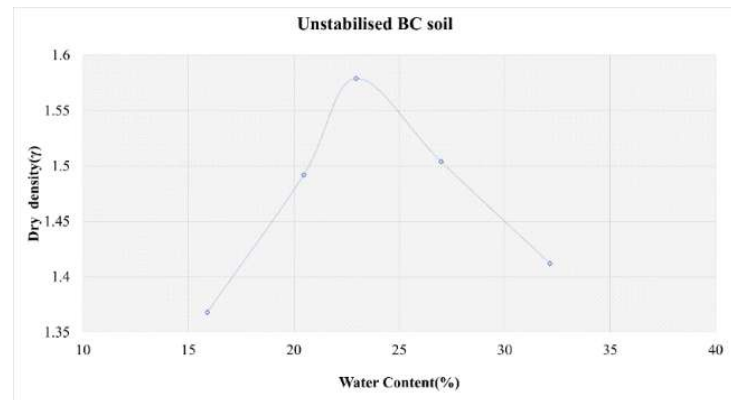

Figure 2. Compaction Behavior of original soil sample

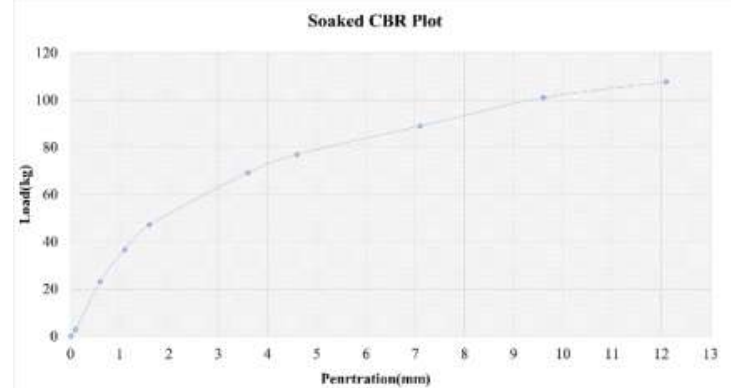

Figure 4. Soaked CBR Behaviour of original soil sample

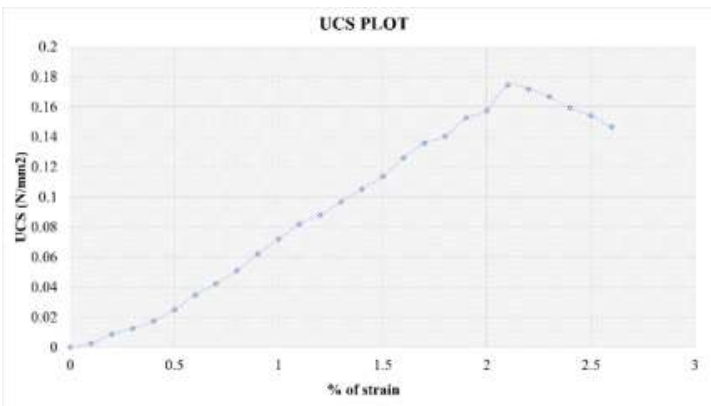

Figure 3. Stress-strain Behavior of original soil sample

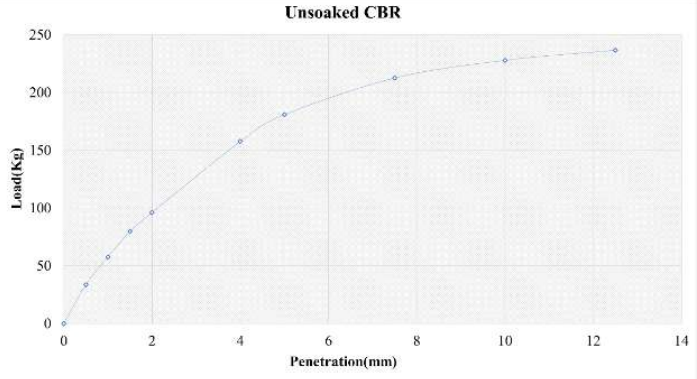

Figure 5. Unsoaked CBR Behaviour of original soil sample

\subsection{Soil Stabilization using GGBS and Lime}

GGBS was added at 5\% and 10\% with corresponding lime at 2, 4, and $6 \%$. After mixing effects on properties like Compaction, Unconfined compressive strength, Soaked CBR was determined.

\subsection{Effect on consistency limits}


The addition of GGBS causes flocculation of clay particles and increases the number of coarser particles which helps in reducing the Atterberg limits. Effect of the increasing percentage of GGBS and Lime on Liquid Limit, Plastic Limit, and Plasticity Index of the original soil sample is done using laboratory tests is summarized in Table 3.

Table 3: Consistency index properties of Soil - GGBS-Lime mix

\begin{tabular}{lllll}
\hline Mix & Liquid Limit & Plastic Limit & Plasticity index & The decrease in Plasticity Index \\
\hline GL-5\&2 & 51.3 & 31.2 & 20 & 5.25 \\
GL-5\&4 & 48.2 & 30.19 & 18.01 & 7.24 \\
GL-5\&6 & 47.3 & 29.74 & 17.56 & 7.65 \\
GL-10\&2 & 48.05 & 30.96 & 17.08 & 8.19 \\
GL-10\&4 & 46.8 & 29.4 & 16 & 9.25 \\
GL-10\&6 & 44.9 & 29.18 & 15.77 & 9.48 \\
\hline
\end{tabular}

The following Figure 6 shows the variation of consistency limits with GGBS and Lime. It is observed that Liquid Limit, Plastic Limit, and Plasticity index decreased with an increase in proportions of stabilizers (see Figure 7. and Figure 8.)

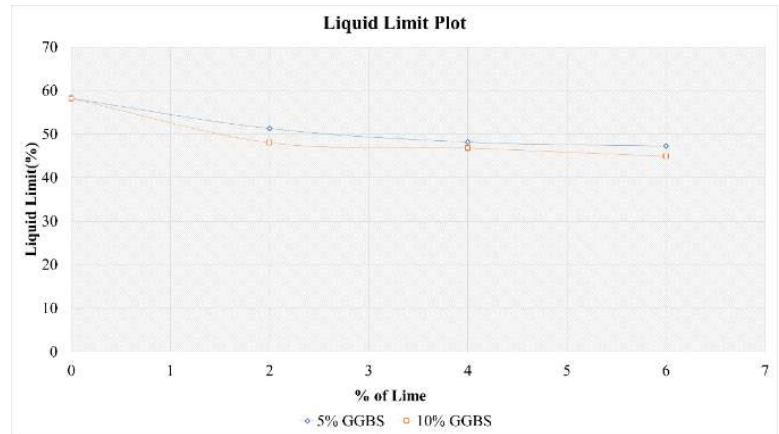

Figure 6. Variation of Liquid Limit with different percentages of GGBS and LIME

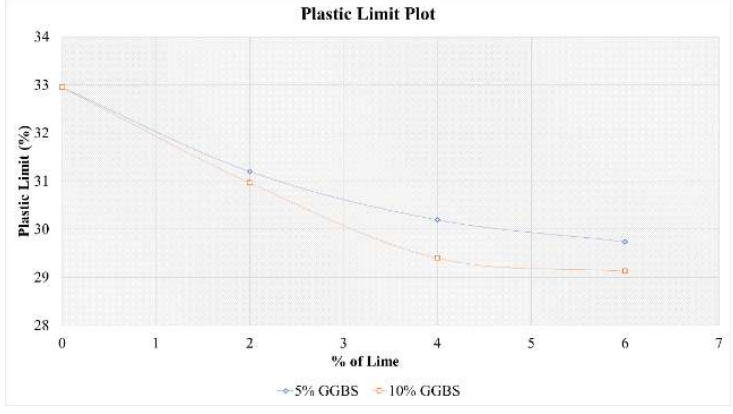

Figure 7. Variation of Plastic Limit with different percentages of GGBS and LIME

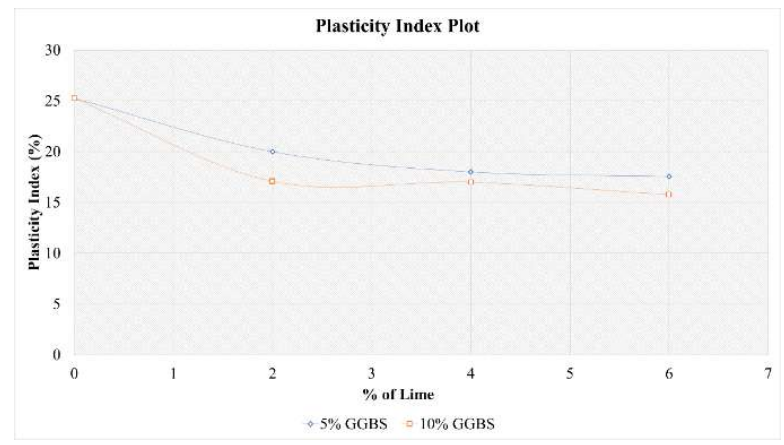

Figure 8. Variation of plasticity index with different percentages of GGBS and LIME

\subsection{Effect on compaction parameters}

Effect of the increasing percentage of GGBS and Lime on OMC and MDD of the original soil sample is done using standard proctor test and is summarized in Table 4.

Table 4. Compaction properties of Soil -GGBS and Lime mix

\begin{tabular}{lll}
\hline Mix & OMC & MDD \\
\hline $100 \%$ soil & 24.10 & 1.585 \\
$93 \%$ soil and GL-5\&2 & 23.35 & 1.647 \\
$91 \%$ soil and GL-5\&4 & 23.2 & 1.584 \\
$89 \%$ soil and GL-5\&6 & 23.15 & 1.576 \\
$88 \%$ soil and GL-10\&2 & 22.2 & 1.596
\end{tabular}




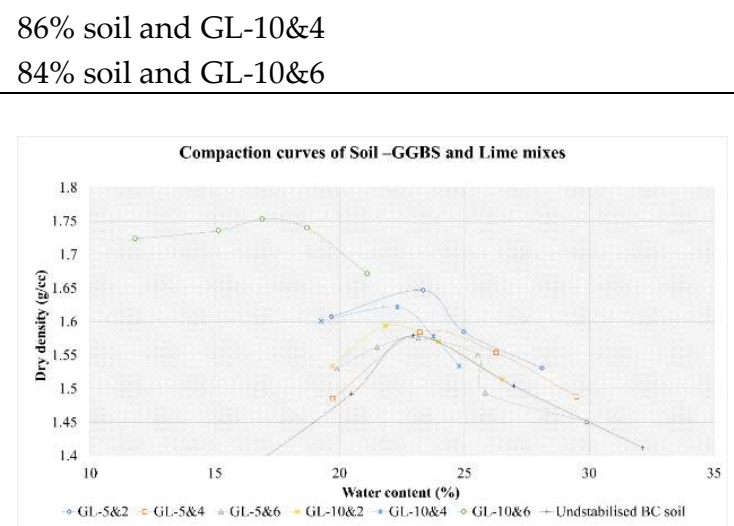

Figure 9. Compaction curves of Soil - GGBS and Lime mixes $\begin{array}{ll}22 & 1.622 \\ 17 & 1.753\end{array}$

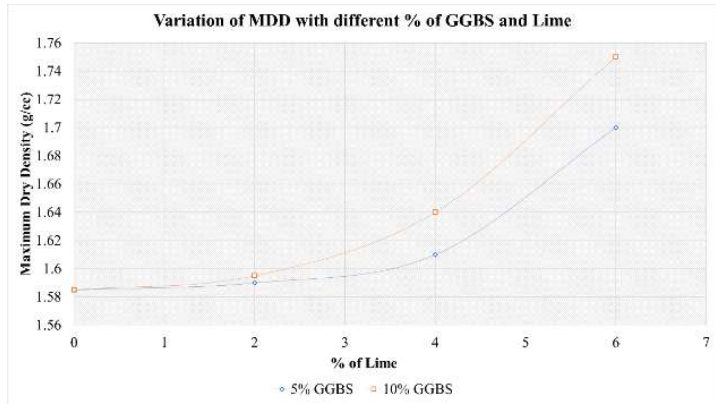

Figure 10. Variation of MDD with different $\%$ of GGBS and Lime

Figure 9. Compaction curves of Soil - GGBS and Lime mixes. Figure 10 shows moisture content -density curves of soil blended with GGBS and Lime. Initial MDD of soil was 1.585 and it got increased at 2, 4, $6 \%$ of Lime with 5\% of GGBS, and MDD increased with at 2, 4, 6\% of Lime with 10\% of GGBS.

\subsection{Effect on Unconfined compressive strength}

This section provides a concise and precise description of the experimental results, their interpretation as well as the experimental conclusions that can be drawn.

UCS test was conducted at increasing quantity of Lime and GGBS at different curing periods that is, $0,7,14,28$ days of curing. Pozzolanic reaction of GGBS and subsequent strength development prolongs for a certain period. GGBS contains siliceous and aluminous materials a. When mixed with black cotton soil, it reacts chemically and forms cementitious compounds.

An increase in the value of UCS is gradual and relatively small for smaller curing periods of 7 and 14 days. The improvement in the UCS is comparatively better for a longer curing period of 28 days. As seen in Table 5. For the same mix of any of the samples, a relative increase in UCS is observed maximum when curing of 28 days is allowed. Within that time a strong matrix of soil Lime and GGBS is formed due to pozzolanic reactions (See Table 5.).

Figure 11. to Figure 14. represents the stress-strain behavior for $0,7,14,28$ days of curing respectively. Its Variation of UCS value on different days of curing is shown in Figure 15.

Table 5. UCS value (KN/m2) of different Soil-LIME-GGBS combination in different days of curing

\begin{tabular}{lllllllll}
\hline $\begin{array}{l}\text { Curing } \\
\text { period (days) } \\
\text { Mix }\end{array}$ & \multicolumn{7}{l}{ Unconfined compressive strength(kPa) } \\
\cline { 2 - 9 } & GL- & GL-5\&4 & GL-5\&6 & Increase in & GL- & GL- & GL- & Increase in \\
& $\mathbf{5 \& 2}$ & & & UCC & 10\&2 & 10\&4 & 10\&6 & UCC \\
\hline 0 & 152.7 & 202.9 & 522.17 & 348.17 & 212.04 & 262 & 578.88 & 404.88 \\
7 & 404.78 & 479.37 & 756.14 & 582.14 & 490.16 & 607.64 & 776.83 & 602.83 \\
14 & 517.78 & 676.35 & 894.60 & 720.6 & 527.92 & 589.04 & 1028.18 & 854.18 \\
28 & 775.50 & 969.46 & 1093.15 & 919.95 & 638.127 & 840.24 & 1273 & 1099 \\
\hline
\end{tabular}
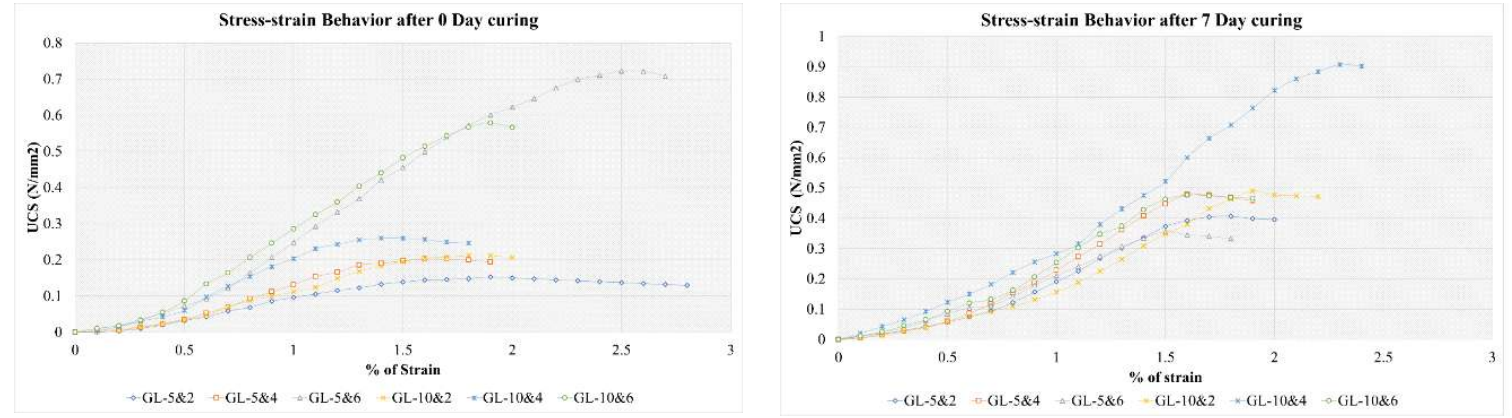
Figure 11. Stress-strain Behaviour of 0 Day curing at different proportions of GGBS and Lime

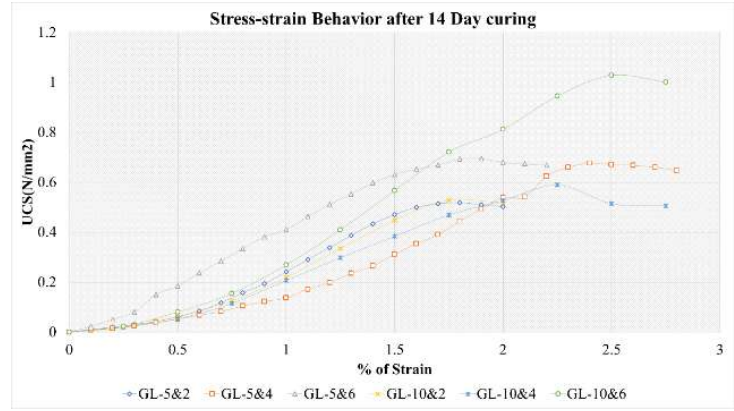

Figure 13. Stress-strain Behaviour of 14 Day curing at different proportions of GGBS and Lime
Figure 12. Stress-strain Behaviour of 7 Day curing at different proportions of GGBS and Lime

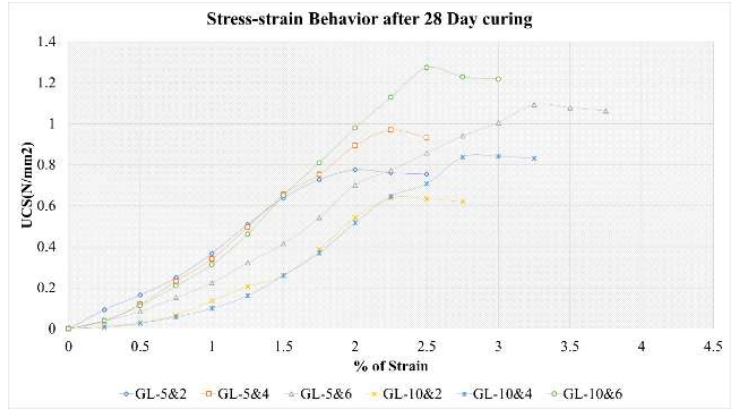

Figure 14. Stress-strain Behaviour of 28 Day curing at different proportions of GGBS and Lime

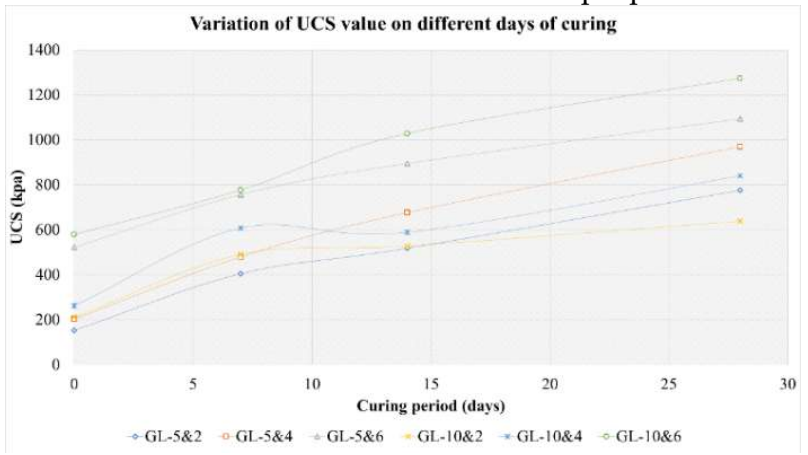

Figure 15. Variation of UCS value on different days of curing

\subsection{Effect on Soaked CBR}

A soaked CBR test was conducted to simulate the worst condition a pavement subgrade can be subjected to. The soil samples were taken after 4 days of soaking (See Figure 18). CBR values of various soil-GGBS-Lime mixes are as shown in Figure 16, Figure 17. and Table 6. CBR values obtained are shown in Table 6 . From the values, it can be observed that the CBR value increased with increases in lime percentages.

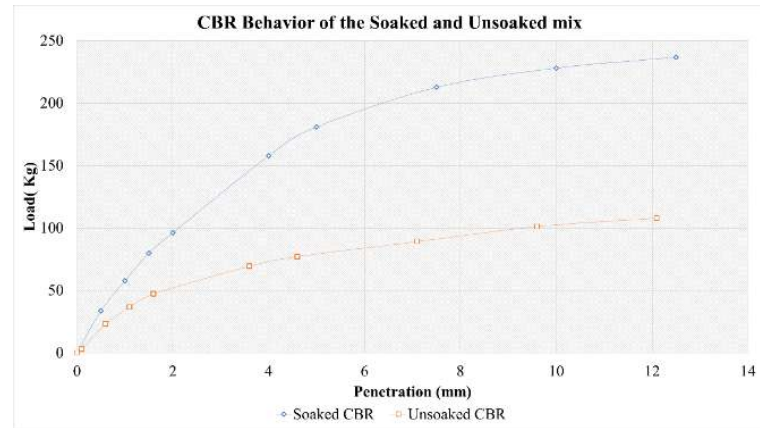

Figure 16. CBR Behaviour of the Soaked and Unsoaked mix

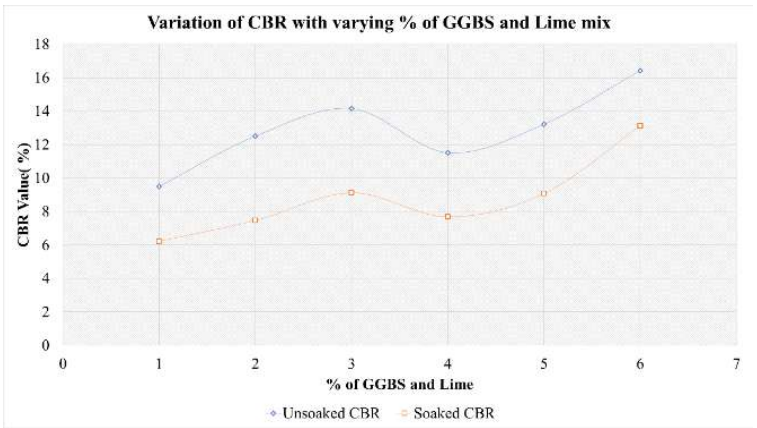

Figure 17. Variation of CBR with varying \% of GGBS and Lime mix

Table 6: CBR characteristics with variation of percentages in GGBS and Lime

\begin{tabular}{lllcc}
\hline Specimen & Unsoaked CBR & Increase in Unsoaked CBR & Soaked CBR & Increase in Soaked CBR \\
\hline GL-5\&2 & 9.504 & 1.484 & 6.216 & 2.11 \\
GL-5\&4 & 12.51 & 4.49 & 7.47 & 2.37 \\
GL-5\&6 & 14.16 & 6.14 & 9.12 & 5.02 \\
GL-10\&2 & 11.52 & 3.5 & 7.68 & 3.58 \\
GL-10\&4 & 13.23 & 5.21 & 9.08 & 4.98 \\
GL-10\&6 & 16.43 & 8.41 & 13.12 & 9.02 \\
\hline
\end{tabular}


The unsoaked CBR value of the soil is determined by mixing with lime and GGBS at optimum moisture content. Testing is done after an immediate mix with stabilizers. Values obtained from experiments are shown in the Table 6. nd their plots are shown in graphs.

\section{Conclusion}

From the above study, the following conclusions are drawn based on the performance of the Black Cotton Soil. Liquid Limit, plastic limit, and plasticity index of soil decreased with the addition of Lime and GGBS. addition of GGBS causes flocculation of clay particles and increases the number of coarser particles which helps in reducing the Atterberg limits The MDD was increased by $9.9 \%$ and the OMC of Block Cotton Soil was by decreased $41.17 \%$. This variation in density is mainly due to high specific gravity and immediate formation of cemented products by hydration which increases the density of soil. The soaked and Un-soaked CBR of soil-Lime and GGBS sample increased by $9.02 \%$ and $8 \%$ respectively with the increase in Lime content and GGBS and found maximum UCS value at proportions $6 \%$ of Lime and GGBS $10 \%$ of GGBS. Unconfined compressive strength of Soil-Lime and GGBS specimen increased by $84.16 \%$ with the increase in Lime content and GGBS and found maximum UCS value at proportions $6 \%$ of Lime and GGBS $10 \%$ of GGBS. The liquid and plastic limits of the expansive soil taken for the study are 58.2 and 32.95 Respectively and the plasticity index was 25.25. The soil sample was classified as clay of high compressibility. The Plasticity Index was reduced by $9.48 \%$. To the original soil sample, an industrial waste slag was added at proportions of 5 and $10 \%$ corresponding to lime of 2,4 , and $6 \%$. The maximum soaked CBR and UCS value obtained after stabilization with GGBS and Lime was increased significantly.

Funding: "This research received no external funding."

Acknowledgments: The authors thank the Osmania University for providing support through laboratory facilities to conduct the experiments presented in this study.

Conflicts of Interest: "The authors declare no conflict of interest."

\section{References}

1. Little, Dallas N., and Syam Nair. "Recommended practice for stabilization of subgrade soils and base materials." (2009).

2. Munfakh, G. A. "Ground improvement in transportation projects: from old visions to innovative applications." Proceedings of the Institution of Civil Engineers-Ground Improvement 7, no. 2 (2003): 47-60.

3. Afrin, Habiba. "A review on different types soil stabilization techniques." International Journal of Transportation Engineering and Technology 3, no. 2 (2017): 19-24.

4. Park, Joo Young. "Assessing determinants of industrial waste reuse: The case of coal ash in the United States." Resources, Conservation and Recycling 92 (2014): 116-127.

5. Wei, Meng-Shiun, and Kuo-Hei Huang. "Recycling and reuse of industrial wastes in Taiwan." Waste management 21, no. 1 (2001): 93-97.

6. Joe, M. Adams, and A. Maria Rajesh. "Soil stabilization using industrial waste and lime." International Journal of Scientific Research Engineering \& Technology (IJSRET) 4, no. 7 (2015).

7. Wild, S., Kinuthia, J. M., Jones, G. I. and Higgins, D. D. (1998). “Effects of partial substitution of lime with ground granulated blast furnace slag (GGBS) on the strength properties of lime-stabilised sulphate-bearing clay soils." Engineering Geology, 51 (1), 37-53.

8. Brooks, Robert M. "Soil stabilization with fly ash and rice husk ash." International Journal of Research and Reviews in Applied Sciences 1, no. 3 (2009): 209-217.

9. Er. Rehana Rasool, Er. Kshipra Kapoor: “COMPARATIVE STUDY ON STABILIZATION OF SOIL WITH GROUND GRANULATED BLAST FURNACE SLAG-GGBS, submitted at International Journal of Latest Research in Science and Technology ISSN (Online):2278-5299Volume 6, Issue 3: Page No.37-4, May-June 2017

10. H. S. Nanda, H.N. Ramesh, H. M. Phalachandra.," Effect of Ground Granulated Blast Furnace Sag on The Geotechnical Properties of Lime Treated Lithomargic Soil". Technology (IJESIT), Volume 1, Issue 1 ISeptember 2016. 
11. Abhijith S, Aruna T published "Effect of Sisal Fibers and GGBS on Strength Properties of Black Cotton Soil" in the International Journal of Innovative Research in Science, Engineering and Technology (An ISO 3297: 2007 Certified Organization) Vol. 4, Issue 7, July 2015

12. Pingili Sravanthi, Shaik Khasim Peera "Black Cotton Soil Stabilization with Ground Granulated Blast Furnace Slag and RBI Grade-81", International Journal of Innovative Research in Science,Engineering and Technology, July 2017, Vol. 6, Issue 7, DOI:10.15680/IJIRSET.2017.0607078

13. T. Geeta Rani, K.Tulasi, Y. Sai Rama Krishna, "Ground granulated blast furnace slag as an expansive soil stabilizer", VFSTR Journal of STEM, (2017), Vol. 03, No. 01.

14. Dayalan.J, (2016), "Comparative study on Stabilization of soil with fly ash and Ground Granulated Blast Furnace Slag (GGBS)", International research journal of engineering and technology (IRJET) vol-3, issue-5, May-2016

15. K.V.ManjunathL.Govindaraju and P.V.Shivapullaiah “ Blast furnace slag for bulk geotechnical applications",Proc. of Indian Geo Technical conference,(2011), Kochi (Paper No.H-098).

16. Harish, G. R. "Studies on stabilization of black cotton soil using lime." International Research Journal of Engineering and Technology 4, no. 6 (2017): 1725-1727.

17. Saravanan, R., T. Udhayakumar, S. Dinesh, C. Venkatasubramanian, and D. Muthu. "Effect of addition of GGBS and lime in soil stabilisation for stabilising local village roads in Thanjavur region." In IOP Conference Series: Earth and Environmental Science, vol. 80, no. 1, p. 012060. IOP Publishing, 2017.

18. IS: 2720(Part 2), 1973 Methods of Test for Soils, Determination of water content.

19. IS 2720(III/SEC-I): 1980 Methods of Test for Soils, Determination of specific gravity.

20. IS 2720(VI I):1980 Methods of Test for Soils, Determination of water content dry Density relation using light compaction.

21. IS 2720(X):1991 Methods of Test for Soils, determination of UCS Test

22. IS 2720(IV):1985 Methods of Test for Soils, determination of grain size analysis.

23. IS 2720-16 (1987): Methods of Test for Soils, Laboratory determination of CBR

24. IS 2720-5-(1985): Methods of Test for Soils, determination of liquid limit and plastic limit.

(C) 2020 by the authors. Submitted for possible open access publication under the terms and conditions of the Creative Commons Attribution (CC BY) license (http://creativecommons.org/licenses/by/4.0/). 